\title{
PRACTICAL MATHEMATICS
}

\section{By CLEMENT V. DURELL, M.A.}

\section{Just published. 200 pages. Price $3 s .3^{d}$.}

Presents in concise form those processes and principles of elementary mathematics which are an essential part of the equipment of all technical students and form the necessary foundation for more specialised work. The book is distinguished by all the characteristics which have given Mr. Durell's mathematical textbooks so high a reputation, and it has been specially planned to meet the needs of those who cannot afford the time to study detailed textbooks of Arithmetic, Algebra, Geometry, Trigonometry and Mechanics. The book merits careful examination by all engaged in teaching mathematics to those who are preparing themselves for technical branches of the armed forces or other forms of national service, and by those responsible for the training of A.T.C. cadets, etc. There is an adequate supply of carefully graded examples : logarithmic and other tables are included.

\section{A NEW GEOMETRY By CLEMENT V. DURELL, M.A.}

Stage $A$, Is. $8 d$. Stage $B, 5 s .3 d$. Together, $6 s .6 d$.

Mr. Durell's new Geometry has been widely adopted, and it is already in its sixth printing. An alternative arrangement is available under the title Exercises and Theorems in Geometry for those who prefer to have Exercises, Constructions and Theorems respectively collected in separate sections of the textbook.

" Once again put the author well into the lead in the field of geometrical teaching. ... A great advance. . . Extraordinarily well planned and graded. . . Admirably set out. The exercises, which are numerous, are very carefully selected and graded and offer ample scope for all types of pupils. . . . Excellent textbooks for all School Certificate Candidates."-Mathematical Gazerte.

\section{G. BELL \& SONS, LTD., PORTUGAL ST., W.C. 2}




\title{
POLISH UP YOUR MATHEMATICS
}

\author{
By R. C. FAWDRY, M.A., B.Sc. ${ }_{5}$ s, net.
}

To-day there are many who would like to revive their interest in mathematics, and many who find that the part it plays in modern warfare is so great that some knowledge of it is essential. $\mathrm{Mr}$. Fawdry's new book aims at giving a general survey of the elementary parts which have a practical bearing in everyday life and which are within the grasp of anyone who takes any interest in the subject. Historical illustrations add to the interest of the book.

\section{PUZZLE PAPERS IN ARITHMETIC}

\section{By F. C. BOON, B.A. Revised edition. rs. $8 d$.}

Comprises 48 papers containing nearly 300 problems, these are of considerable variety, though few require any mathematical knowledge. "The author's claim that the "pupils evince a sprightlier attitude which quickens their pace in the formal work ' is amply justified and the intriguing nature of the problems contributes largely towards this. It is no exaggeration to say that every teacher of school mathematics should use the book regularly."

Mathematical Gazette.

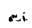

\section{MATHEMATICAL TABLES}

\section{Compiled by C. V. DURELL, M.A. $4^{\circ} p$. rod.}

"A complete set of four-figure tables containing all the tables that the average secondary student is likely to require, clearly printed.

The 'Difference Columns' in many books of tables give a fallacious appearance of accuracy at times when the differences are changing rapidly Accordingly, in this book, where necessary, the tables give the average difference for ${ }^{\prime}$, calculated over $\mathrm{I}^{\prime}{ }^{\prime}$ intervals instead of intervals of $x^{\circ}$ The use of these difference columns is just as easily learnt and their superior accuracy is evident."-Journal of Education.

\section{G. BELL \& SONS, LTD., PORTUGAL ST., W.C. 2}

